in vivo $34: 489-494(2020)$

doi:10.21873/invivo.11799

\title{
Oral Recombinant Methioninase Prevents Obesity in Mice on a High-fat Diet
}

\author{
YOSHIHIKO TASHIRO ${ }^{1,2,3}$, QINGHONG HAN ${ }^{1}$, YUYING TAN ${ }^{1}$, NORIHIKO SUGISAWA ${ }^{1,3}$, \\ JUN YAMAMOTO ${ }^{1,3}$, HIROTO NISHINO ${ }^{1,3}$, SACHIKO INUBUSHI ${ }^{1,3}$, TAKASHI HIGUCHI ${ }^{1,3}$, \\ TAKESHI AOKI ${ }^{2}$, MASAHIKO MURAKAMI ${ }^{2}$ and ROBERT M. HOFFMAN ${ }^{1,3}$ \\ ${ }^{1}$ AntiCancer Inc, San Diego, CA, U.S.A.; \\ ${ }^{2}$ Department of General and Gastroenterological Surgery, Showa University School of Medicine, Tokyo, Japan; \\ ${ }^{3}$ Department of Surgery, University of California, San Diego, CA, U.S.A.
}

\begin{abstract}
Background/Aim: obesity is a world-wide recalcitrant problem leading to many diseases. Dietary methionine restriction (MR) has been shown to prevent obesity, but it is an onerous regimen. The present study aimed to determine the effects of oral recombinant methionase (o-rMETase), on preventing obesity in mice on a high-fat diet. Materials and Methods: Male C57BL/6J mice in the control group were fed a control diet $(C D)(+6.5 \%$ fat) for 25 days, and others were fed a high-fat (HF) diet (+34.3\% fat) for 25 days. Then, the mice were divided into three dietary groups: 1) $H F+$ phosphate buffered saline (PBS) group; 2) HF +o-rMETase group; and 3) untreated non-HF group. Results: The mice on the CD increased in body weight by $14 \%$ during experimental period of 25 days; in contrast the mice in the HF+PBS group increased by 33\%; however, the mice on the HF+o-rMETase group increased only by $14 \%$ ( $p=0.02, H F+P B S$ vs $H F+o-$ rMETase). Conclusion: The HF+o-rMETase group had the same weight increase as untreated mice on a normal fat diet, demonstrating the potential for o-rMETase to eliminate the need for dieting to maintain normal body weight.
\end{abstract}

The obesity population is rapidly increasing throughout the world (1). The World Health Organization (WHO) estimated

This article is freely accessible online.

Correspondence to: Robert M. Hoffman, Ph.D., AntiCancer Inc, 7917 Ostrow St, San Diego, CA, 92111, U.S.A. Tel: +1 8586542555, Fax: +1 8582684175, e-mail: all@anticancer.com and Takeshi Aoki, MD, Ph.D., Department of General and Gastroenterological Surgery, Showa University School of Medicine, 1-5-8 Hatanodai, Shinagawaku, Tokyo 142-8666, Japan. Tel: +81 337848000, Fax: +81 489653019, e-mail: takejp@med.showa-u.ac.jp

Key Words: Methioninase, methionine restriction, MR, obesity, high fat diet, mice. in 2016, more than 1.9 billion adults aged 18 years and older were overweight (BMI $>25$ ), and of these over 650 million were obese (BMI >30). Approximately $13 \%$ of the world's adult population was obese in 2016; the world prevalence of obesity nearly tripled in about 40 years (2). Excess weight is often accompanied by high blood pressure, high blood cholesterol, type 2 diabetes, coronary heart disease, and other health problems. The total cost attributable to obesity-related diseases approaches $\$ 100$ billion annually in the US.

Dietary methionine restriction (MR) has prevented weight gain in mice and humans $(3,4)$. The potential health benefits of vegan and vegetarian diets may be linked to a lower methionine intake. Lowering methionine intake to levels characteristic of vegan diets, which have naturally low methionine levels $(5,6)$, may be associated with health benefits, including lower rates of obesity (7).

However, it is difficult to maintain dietary restriction in daily life. Dropout is a serious problem in weight-loss intervention programs for obese patients and up to $80 \%$, depending on the type and setting of the treatment program (8-12), regained the lost weight or more. Bariatric surgery is wide-spread as a therapy for severe obesity and refractory diabetes. However, there are some complications, and obesity and diabetes recur at a constant rate after surgery $(13,14)$.

Dietary MR involves severe protein restriction and is unpalatable to most patients for cancer therapy. Enzymatic MR has also been described with methioninase (L-metionine $\alpha$-deamino- $\gamma$-mercaptomethane lyase) (15-19). Our laboratory has developed recombinant methioninase (rMETase) with the Pseudomonas putida gene inserted in Escherichia coli and has targeted cancer in mouse models with high efficacy, especially in combination with chemotherapy (16-19). However enzymatic MR has limited potential as an injectable foreign protein.

Our laboratory has recently developed oral rMETase (orMETase) which has been shown to be highly effective in mouse models of cancer as injectable o-rMETase (20-27). In 
the present report, we show that o-rMETase prevents obesity in mice on a high-fat diet, thereby opening a new paradigm for obesity prevention.

\section{Materials and Methods}

Animal studies. C57BL/6 mice aged 8 weeks were used in this study. Mice were housed in a barrier facility on a high efficacy particulate air (HEPA)-filtered rack under standard conditions of 12-h light/dark cycles. Animal studies were performed with an AntiCancer Institutional Animal Care and Use Committee (IACUC)-protocol specially approved for this study and in accordance with the principles and procedures outlined in the National Institutes of Health Guide for the Care and Use of Animals under Assurance Number A3873-1.

Recombinant methioninase. Recombinant L-metionine $\alpha$-deamino$\gamma$-mercaptomethane lyase [recombinant methioninase, (rMETase)] [EC 4.4.1.11] from Pseudomonas putida has been previously cloned and was produced in Escherichia coli (AntiCancer, Inc., San Diego, CA, USA). rMETase is a homotetrameric PLP enzyme of $172-\mathrm{kDa}$ molecular mass (16).

Study design. Mice were randomized into three groups of 5 mice (Figure 1); standard diet (6.5\% fat) without treatment $(\mathrm{n}=5)$; high-fat (HF) diet (34.3\% fat), treated with phosphate-buffer saline (PBS) by oral gavage $(n=5)$; HF diet with rMETase (100 units, per dose, twice a day, 25 consecutive days, oral gavage $n=5)$. C57BL/6 mice were fed either a standard global rodent diet (Harlan Teklad 2020x) or HF diet chow containing 60\% kcal from fat (Harlan Teklad TD.06414) for 25 days. Each mouse was given the experimental diet in accordance with a pair-feeding protocol. Therefore, daily food intake, and energy, protein and fat intake did not differ among the groups (Figure 2B).

Body weight and calorie intake. Body weight and dietary intake were recorded daily.

Methionine calculation. Methionine was determined with an HPLC procedure described previously $(28,29)$.

Statistical analyses. All data are presented as means \pm standard error of the mean (SEM). Student's $t$-tests were performed. $p<0.05$ is considered significant.

\section{Results}

Efficacy of o-rMETase on the high-fat diet mice to prevent obesity in mice. The mice on the control diet (CD) had a weight gain of $14 \%$ as they grew normally. The mice on the high-fat (HF) diet, in contrast, had a weight gain of $33 \%$, approximately, $124 \%$ more than mice on the CD. However, the mice on the HF diet treated with o-rMETase gained only $14 \%$ body weight, the same as mice on the CD. o-rMETase could enable the mice to have normal weight despite being on the HF diet. ( $p=0.02$ ) (Figure2A and Figure 3).

o-rMETase regulates blood methionine levels. o-rMETase reduces blood methionine levels to approximately $20 \%$ within 3 h compared to pre-o-rMETase level (Figure 4),

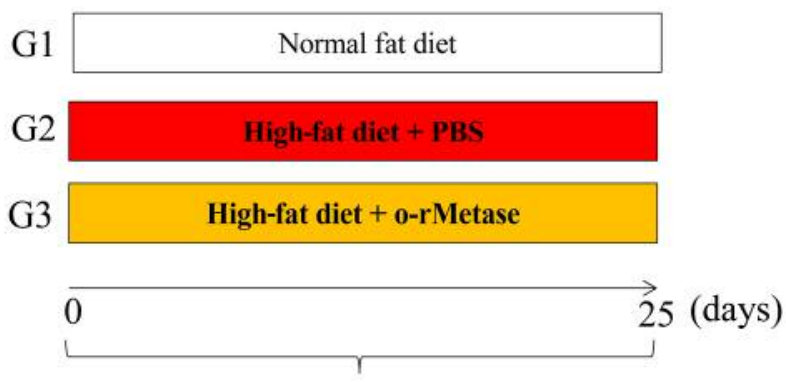

Measurement of body weight and amount of each diet every day

Figure 1. Treatment protocol. G1: normal fat diet + untreated control $(n=5)$; G2: High fat diet + PBS (50 $\mu$ l/dose, twice a day, oral gavage, daily); G3: High fat diet +o-rMETase (50 units/ dose, twice a day, oral gavage).

\section{Discussion}

Drug therapy, cognitive behavioral therapy and diet therapy are used for body weight loss for obesity patients. These therapies are temporarily efficient, with a high dropout rate (8-11, 12, 30). Body weight easily rebounds because it is difficult to maintain these regimens (31). Recently bariatric surgery has become wide-spread for obesity patients, but often involves complications.

Methionine is an essential amino acid that is absorbed in the small intestine. The absorbed methionine is used for protein synthesis and converted to S-adenosylmethionine, which plays an important role in DNA and other methylation and metabolic reactions. In general, a vegan diet has a low amount of methionine and several studies have suggested it has health benefits $(6,7)$. Dietary MR has many positive effects on metabolic health and has been shown to extend lifespan in rodents (32-34). However, it is difficult to maintain dietary MR in daily life, and we should consider the resulting high drop-out rate and weight rebound after MR.

METase was initially purified from Clostridium sporogene and catabolized methionine to $\alpha$-ketobutyrate, methanethiol and ammonia (15). rMETase was developed to lower the methionine levels in vivo. Our laboratory developed rMETase from Pseudomonas putida, cloned in Escherichia coli, as a very efficient means of MR (16). A big advance was our laboratory's development of o-rMETase which makes administration safe and easy without side-effects $(20,21-27)$.

The present study is the first demonstration of efficacy of o-rMETase to prevent obesity in mice on a high fat diet. In the present study, the body weight gain of o-rMETase-treated mice on a high-fat diet was significantly less than PBStreated mice on a high fat diet (Figure 2A) and no more than untreated mice on a low-fat diet.

o-rMETase reduces $80 \%$ methinonine levels within $3 \mathrm{~h}$ (Figure 4). Therefore o-rMET is a more powerful, means of 

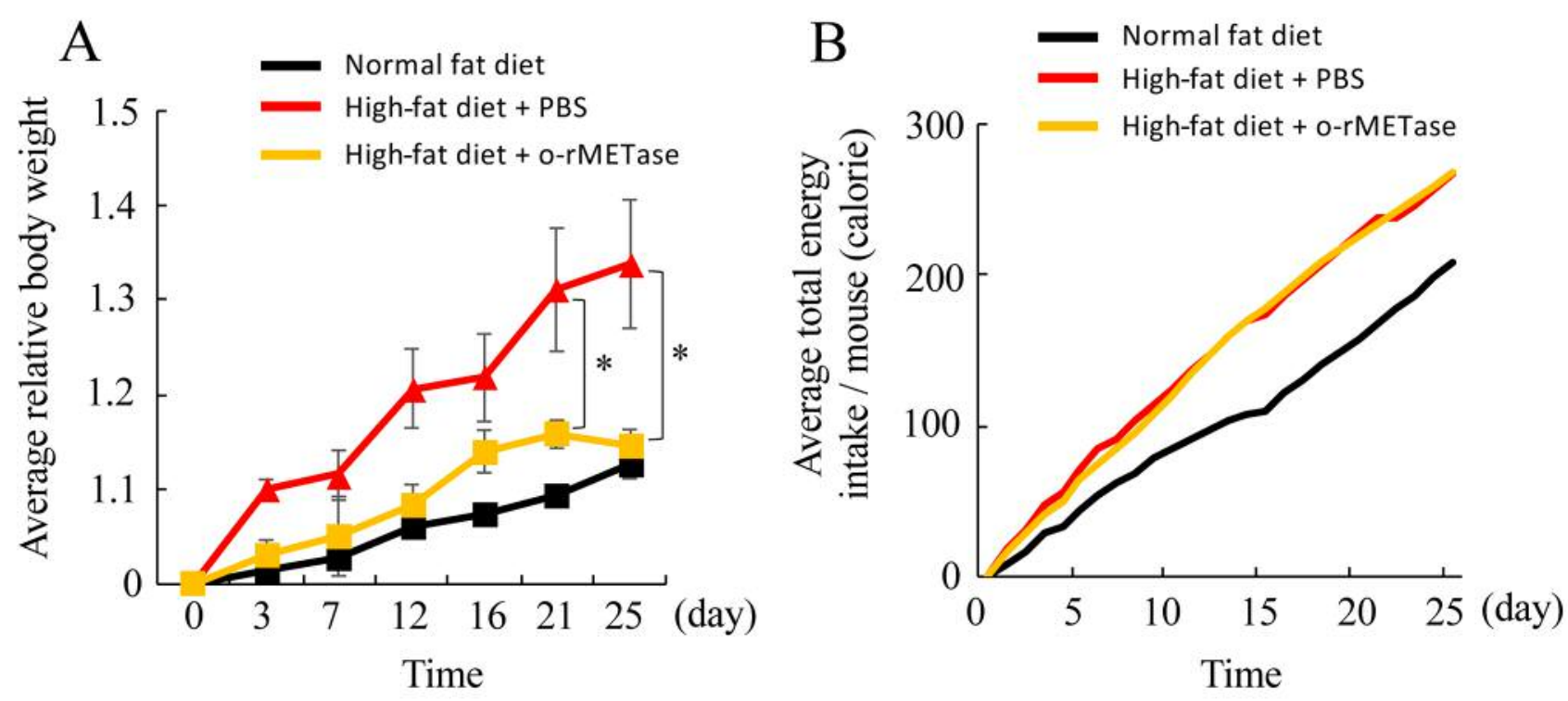

Figure 2. o-rMETase prevents obesity. (A) Relative average body weight ( $+S E M, n=5$ mice). (B) Average total energy intake by mice. * $p<0.05$.

o-rMETase

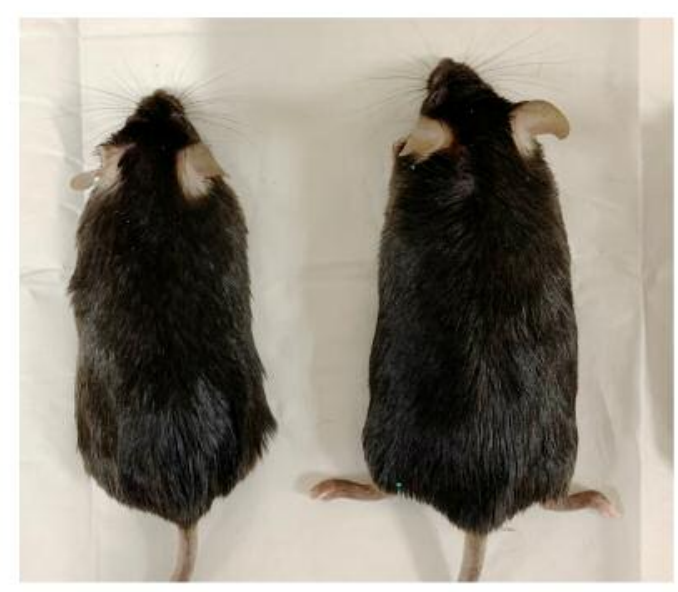

o-rMETase

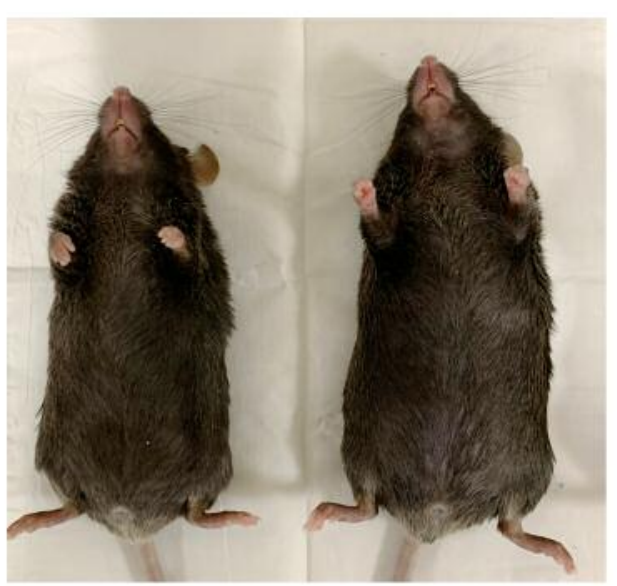

Figure 3. Mice on a high-fat diet.

MR than a low methionine diet (35). o-rMETase administration eliminates the need for dietary MR.

Thus, o-rMETase may be a new beneficial strategy for obesity patients and possibly other metabolic diseases associated with obesity. o-rMETase has the potential to eliminate the need for dieting to maintain body weight.

\section{Conclusion}

In summary, we demonstrated for the first time the efficacy of o-rMETase to prevent obesity in mice on a high fat diet.

\section{Authors' Contributions}

Y.T., S.R.S and R.M.H designed and performed experiments, analyzed data and wrote the paper; Q.H., M.Z. and Y.T. provided reagents; N.S., J.Y., H.N., A.T., M.M., M.B. and H.N. gave technical support and conceptual advice.

\section{Conflicts of Interest}

The Authors declare no competing financial interests. 


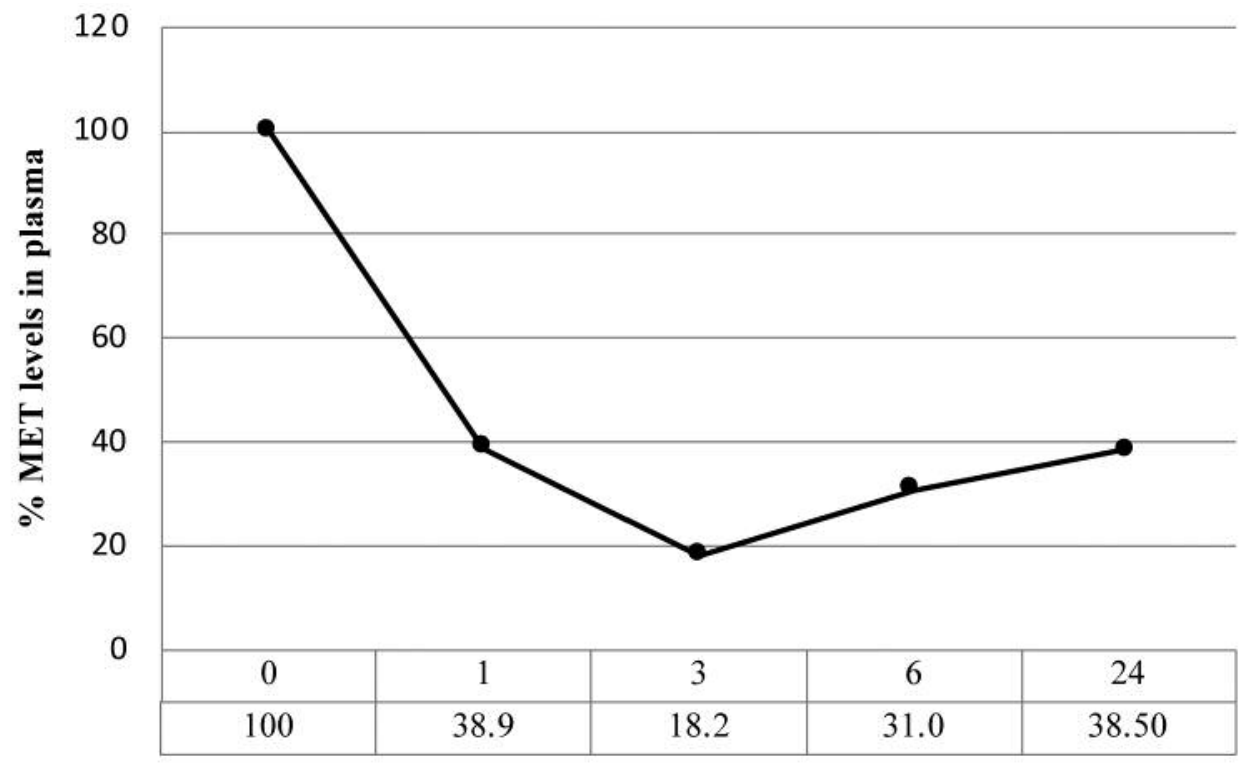

Figure 4. Time course of methionine depletion in mouse plasma after o-rMETase. 50 units of o-rMETase, twice a day and overnight fasting.

\section{Acknowledgements}

This paper is dedicated to the memory of A. R. Moossa, M.D., Sun Lee, M.D., Professor Li Jiaxi, and Masaki Kitajima, MD.

\section{References}

1 Afshin A, Reitsma MB and Murray CJL: Health effects of overweight and obesity in 195 countries. N Engl J Med 377(15): 1496-1497, 2017. PMID: 29020584. DOI: 10.1056/NEJMc1710026

2 Organization WH: Fact sheet: Obesity and overweight. Available at: https://www.who.int/en/news-room/fact-sheets/detail/obesityand-overweight (Last accessed 3 January 2005), 2016.

3 Brown-Borg HM and Buffenstein R: Cutting back on the essentials: Can manipulating intake of specific amino acids modulate health and lifespan? Ageing Res Rev 39: 87-95, 2017. PMID: 27570078. DOI: 10.1016/j.arr.2016.08.007

4 Stone KP, Wanders D, Orgeron M, Cortez CC and Gettys TW: Mechanisms of increased in vivo insulin sensitivity by dietary methionine restriction in mice. Diabetes 63(11): 3721-3733, 2014. PMID: 24947368. DOI: 10.2337/db14-0464

5 McCarty MF, Barroso-Aranda J and Contreras F: The lowmethionine content of vegan diets may make methionine restriction feasible as a life extension strategy. Med Hypotheses 72(2): 125-128, 2009. PMID: 18789600. DOI: 10.1016/ j.mehy.2008.07.044

6 Schmidt JA, Rinaldi S, Scalbert A, Ferrari P, Achaintre D, Gunter MJ, Appleby PN, Key TJ and Travis RC: Plasma concentrations and intakes of amino acids in male meat-eaters, fish-eaters, vegetarians and vegans: A cross-sectional analysis in the epic-oxford cohort. Eur J Clin Nutr 70(3): 306-312, 2016. PMID: 26395436. DOI: 10.1038/ejen.2015.144
7 Fraser GE: Vegetarian diets: What do we know of their effects on common chronic diseases? Am J Clin Nutr 89(5): 1607s1612s, 2009. PMID: 19321569. DOI: 10.3945/ajcn.2009.26736K

8 Dalle Grave R, Calugi S, Molinari E, Petroni ML, Bondi M, Compare A and Marchesini G: Weight loss expectations in obese patients and treatment attrition: An observational multicenter study. Obes Res 13(11): 1961-1969, 2005. PMID: 16339128. DOI: $10.1038 /$ oby.2005.241

9 Bennett GA and Jones SE: Dropping out of treatment for obesity. J Psychosom Res 30(5): 567-573, 1986. PMID: 3772838. DOI: 10.1016/0022-3999(86)90029-2

10 Inelmen EM, Toffanello ED, Enzi G, Gasparini G, Miotto F, Sergi G and Busetto L: Predictors of drop-out in overweight and obese outpatients. Int J Obes (Lond) 29(1): 122-128, 2005. PMID: 15545976. DOI: 10.1038/sj.ijo.0802846

11 Huisman S, Maes S, De Gucht VJ, Chatrou M and Haak HR: Low goal ownership predicts drop-out from a weight intervention study in overweight patients with type 2 diabetes. Int J Behav Med 17(3): 176-181, 2010. PMID: 20033629. DOI: 10.1007/s12529-009-9071-3

12 Sawamoto R, Nozaki T, Furukawa T, Tanahashi T, Morita C, Hata T, Komaki G and Sudo N: Predictors of dropout by female obese patients treated with a group cognitive behavioral therapy to promote weight loss. Obes Facts 9(1): 29-38, 2016. PMID: 26745715. DOI: $10.1159 / 000442761$

13 Viscido G, Gorodner V, Signorini FJ, Biasoni AC, Navarro L, Rubin G, Obeide L and Moser F: Obese patients with type 2 diabetes: Outcomes after laparoscopic sleeve gastrectomy. J Laparoendosc Adv Surg Tech A 29(5): 655-662, 2019. PMID: 30452318. DOI: $10.1089 /$ lap.2018.0652

14 Souteiro P, Belo S, Magalhaes D, Pedro J, Neves JS, Oliveira SC, Freitas P, Varela A and Carvalho D: Long-term diabetes outcomes after bariatric surgery-managing medication withdrawl. Int $\mathbf{J}$ 
Obes (Lond), 2019. PMID: 30696933. DOI: 10.1038/s41366019-0320-5

15 Kreis W and Hession C: Isolation and purification of 1methionine-alpha-deamino-gamma-mercaptomethane-lyase (1methioninase) from clostridium sporogenes. Cancer Res 33(8): 1862-1865, 1973. PMID: 4720797.

16 Tan Y, Xu M, Tan X, Tan X, Wang X, Saikawa Y, Nagahama T, Sun X, Lenz M and Hoffman RM: Overexpression and largescale production of recombinant 1-methionine-alpha-deaminogamma-mercaptomethane-lyase for novel anticancer therapy. Protein Expr Purif 9(2): 233-245, 1997. PMID: 9056489. DOI: 10.1006/prep.1996.0700

17 Igarashi K, Kawaguchi K, Kiyuna T, Miyake K, Murakami T, Yamamoto N, Hayashi K, Kimura H, Miwa S, Tsuchiya $\mathrm{H}$ and Hoffman RM: Effective metabolic targeting of human osteosarcoma cells in vitro and in orthotopic nude-mouse models with recombinant methioninase. Anticancer Res 37(9): $4807-$ 4812, 2017. PMID: 28870899. DOI: 10.21873/anticanres.11887

18 Igarashi K, Kawaguchi K, Li S, Han Q, Tan Y, Gainor E, Kiyuna T, Miyake K, Miyake M, Higuchi T, Oshiro H, Singh AS, Eckardt MA, Nelson SD, Russell TA, Dry SM, Li Y, Yamamoto N, Hayashi K, Kimura H, Miwa S, Tsuchiya H, Eilber FC and Hoffman RM: Recombinant methioninase combined with doxorubicin (dox) regresses a dox-resistant synovial sarcoma in a patient-derived orthotopic xenograft (pdox) mouse model. Oncotarget 9(27): 19263-19272, 2018. PMID: 29721200. DOI: 10.18632 /oncotarget.24996

19 Igarashi K, Li S, Han Q, Tan Y, Kawaguchi K, Murakami T, Kiyuna T, Miyake K, Li Y, Nelson SD, Dry SM, Singh AS, Elliott IA, Russell TA, Eckardt MA, Yamamoto N, Hayashi K, Kimura H, Miwa S, Tsuchiya H, Eilber FC and Hoffman RM: Growth of doxorubicin-resistant undifferentiated spindle-cell sarcoma pdox is arrested by metabolic targeting with recombinant methioninase. J Cell Biochem 119(4): 3537-3544, 2018. PMID: 29143983. DOI: $10.1002 /$ jcb.26527

20 Higuchi T, Kawaguchi K, Miyake K, Han Q, Tan Y, Oshiro H, Sugisawa N, Zhang Z, Razmjooei S, Yamamoto N, Hayashi K, Kimura H, Miwa S, Igarashi K, Chawla SP, Singh AS, Eilber FC, Singh SR, Tsuchiya H and Hoffman RM: Oral recombinant methioninase combined with caffeine and doxorubicin induced regression of a doxorubicin-resistant synovial sarcoma in a pdox mouse model. Anticancer Res 38(10): 5639-5644, 2018. PMID: 30275182. DOI: 10.21873/anticanres.12899

21 Kawaguchi K, Han Q, Li S, Tan Y, Igarashi K, Kiyuna T, Miyake K, Miyake M, Chmielowski B, Nelson SD, Russell TA, Dry SM, Li Y, Singh AS, Eckardt MA, Unno M, Eilber FC and Hoffman RM: Targeting methionine with oral recombinant methioninase (ormetase) arrests a patient-derived orthotopic xenograft (pdox) model of braf-v600e mutant melanoma: Implications for chronic clinical cancer therapy and prevention. Cell Cycle 17(3): 356-361, 2018. PMID: 29187018. DOI: 10.1080/15384101.2017.1405195

22 Kawaguchi K, Miyake K, Han Q, Li S, Tan Y, Igarashi K, Kiyuna T, Miyake M, Higuchi T, Oshiro H, Zhang Z, Razmjooei S, Wangsiricharoen S, Bouvet M, Singh SR, Unno M and Hoffman $\mathrm{RM}$ : Oral recombinant methioninase (o-rmetase) is superior to injectable rmetase and overcomes acquired gemcitabine resistance in pancreatic cancer. Cancer Lett 432: 251-259, 2018. PMID: 29928962. DOI: 10.1016/j.canlet.2018.06.016

23 Higuchi T, Oshiro H, Miyake K, Sugisawa N, Han Q, Tan Y, Park J, Zhang Z, Razmjooei S, Yamamoto N, Hayashi K,
Kimura H, Miwa S, Igarashi K, Bouvet M, Chawla SP, Singh SR, Tsuchiya $\mathrm{H}$ and Hoffman RM: Oral recombinant methioninase, combined with oral caffeine and injected cisplatinum, overcome cisplatinum-resistance and regresses patient-derived orthotopic xenograft model of osteosarcoma. Anticancer Res 39(9): 4653-4657, 2019. PMID: 31519563. DOI: 10.21873/anticanres.13646

24 Higuchi T, Sugisawa N, Yamamoto J, Oshiro H, Han Q, Yamamoto N, Hayashi K, Kimura H, Miwa S, Igarashi K, Tan Y, Kuchipudi S, Bouvet M, Singh SR, Tsuchiya H and Hoffman RM: The combination of oral-recombinant methioninase and azacitidine arrests a chemotherapy-resistant osteosarcoma patient-derived orthotopic xenograft mouse model. Cancer Chemother Pharmacol, 2019. PMID: 31705268. DOI: 10.1007/s00280-019-03986-0

25 Oshiro H, Tome Y, Kiyuna T, Yoon SN, Lwin TM, Han Q, Tan Y, Miyake K, Higuchi T, Sugisawa N, Katsuya Y, Park JH, Zang Z, Razmjooei S, Bouvet M, Clary B, Singh SR, Kanaya F, Nishida $\mathrm{K}$ and Hoffman RM: Oral recombinant methioninase overcomes colorectal-cancer liver metastasis resistance to the combination of 5-fluorouracil and oxaliplatinum in a patientderived orthotopic xenograft mouse model. Anticancer Res 39(9): 4667-4671, 2019. PMID: 31519565. DOI: 10.21873/ anticanres. 13648

26 Park JH, Han Q, Zhao M, Tan Y, Higuchi T, Yoon SN, Sugisawa N, Yamamoto J, Bouvet M, Clary B, Singh SR and Hoffman RM: Oral recombinant methioninase combined with oxaliplatinum and 5-fluorouracil regressed a colon cancer growing on the peritoneal surface in a patient-derived orthotopic xenograft mouse model. Tissue Cell 61:109-114, 2019. PMID: 31759402. DOI: 10.1016/j.tice.2019.09.006

27 Park JH, Zhao M, Han Q, Sun Y, Higuchi T, Sugisawa N, Yamamoto J, Singh SR, Clary B, Bouvet M and Hoffman RM: Efficacy of oral recombinant methioninase combined with oxaliplatinum and 5-fluorouracil on primary colon cancer in a patient-derived orthotopic xenograft mouse model. Biochem Biophys Res Commun 518(2): 306-310, 2019. PMID: 31421825. DOI: $10.1016 /$ j.bbrc.2019.08.051

28 Murakami T, Li S, Han Q, Tan Y, Kiyuna T, Igarashi K, Kawaguchi K, Hwang HK, Miyake K, Singh AS, Nelson SD, Dry SM, Li Y, Hiroshima Y, Lwin TM, DeLong JC, Chishima T, Tanaka K, Bouvet M, Endo I, Eilber FC and Hoffman RM: Recombinant methioninase effectively targets a ewing's sarcoma in a patient-derived orthotopic xenograft (pdox) nude-mouse model. Oncotarget 8(22): 35630-35638, 2017. PMID: 28404944. DOI: 10.18632 /oncotarget.15823

29 Sun X, Tan Y, Yang Z, Li S and Hoffman RM: A rapid hplc method for the measurement of ultra-low plasma methionine concentrations applicable to methionine depletion therapy. Anticancer Res 25(1a): 59-62, 2005. PMID: 15816519.

30 Clinical guidelines on the identification, evaluation, and treatment of overweight and obesity in adults - the evidence report. National institutes of health. Obes Res 6(Suppl 2): 51s209s, 1998. PMID: 9813653.

31 Wing RR, Bolin P, Brancati FL, Bray GA, Clark JM, Coday M, Crow RS, Curtis JM, Egan CM, Espeland MA, Evans M, Foreyt JP, Ghazarian S, Gregg EW, Harrison B, Hazuda HP, Hill JO, Horton ES, Hubbard VS, Jakicic JM, Jeffery RW, Johnson KC, Kahn SE, Kitabchi AE, Knowler WC, Lewis CE, MaschakCarey BJ, Montez MG, Murillo A, Nathan DM, Patricio J, Peters 
A, Pi-Sunyer X, Pownall H, Reboussin D, Regensteiner JG, Rickman AD, Ryan DH, Safford M, Wadden TA, Wagenknecht LE, West DS, Williamson DF and Yanovski SZ: Cardiovascular effects of intensive lifestyle intervention in type 2 diabetes. $\mathrm{N}$ Engl J Med 369(2): 145-154, 2013. PMID: 23796131. DOI: 10.1056/NEJMoa1212914

32 Malloy VL, Perrone CE, Mattocks DA, Ables GP, Caliendo NS, Orentreich DS and Orentreich N: Methionine restriction prevents the progression of hepatic steatosis in leptin-deficient obese mice. Metabolism 62(11): 1651-1661, 2013. PMID: 23928105. DOI: $10.1016 /$ j.metabol.2013.06.012

33 Ables GP, Perrone CE, Orentreich D and Orentreich N: Methionine-restricted $\mathrm{c} 57 \mathrm{bl} / 6 \mathrm{j}$ mice are resistant to diet-induced obesity and insulin resistance but have low bone density. PLoS One 7(12): e51357, 2012. PMID: 23236485. DOI: 10.1371/ journal.pone. 0051357
34 Malloy VL, Krajcik RA, Bailey SJ, Hristopoulos G, Plummer JD and Orentreich N: Methionine restriction decreases visceral fat mass and preserves insulin action in aging male fischer 344 rats independent of energy restriction. Aging Cell 5(4): 305-314, 2006. PMID: 16800846. DOI: 10.1111/j.1474-9726.2006.00220.x

35 Gao X, Sanderson SM, Dai Z, Reid MA, Cooper DE, Lu M, Richie JP, Jr., Ciccarella A, Calcagnotto A, Mikhael PG, Mentch SJ, Liu J, Ables G, Kirsch DG, Hsu DS, Nichenametla SN and Locasale JW: Dietary methionine influences therapy in mouse cancer models and alters human metabolism. Nature 572(7769): 397-401, 2019. PMID: 31367041. DOI: 10.1038/s41586-019-1437-3

Received December 3, 2019

Revised December 10, 2019

Accepted December 13, 2019 